\title{
A METÁFORA NA LÍNGUA BRASILEIRA DE SINAIS: UM ESTUDO BIBLIOGRÁFICO
}

The metaphor in the Brazilian Sign Language: an outline

\section{Darlice da Silva Monte ${ }^{1}$}

\begin{abstract}
RESUMO: Muitas especulações circundam a Língua Brasileira de Sinais (LIBRAS) e muitas relacionam-se às suas características linguísticas, dentre elas está o questionamento referente à concretização da metáfora em uma língua não oralizada. Fato complexo com ramificações em áreas diversas incluindo a linguística e a interligação da educação com a cultura. O presente trabalho buscou embasamento em autores renomados que comprovam a presença de metáforas na língua Brasileira de Sinais; mostram a importância do contexto sócio - cultural e da pragmática para a compreensão de metáforas de modo a evitar comprometimento na compreensão do significado destinado à metáfora em determinado contexto se os envolvidos não compartilharem de um mesmo meio cultural. Discute-se ainda, o fato de a metáfora ser vista como figura de linguagem e destaca-se das demais por acreditar-se que a mesma fornece subsídios ou mesmo origem a outras figuras. Um trabalho bibliográfico que enfatiza um artifício linguístico muito utilizado no cotidiano em variadas circunstâncias a ponto de confundir-se com a própria linguagem.
\end{abstract}

PALAVRAS-CHAVE: Língua Brasileira de Sinais (LIBRAS); Metáfora; Contexto.

\begin{abstract}
Many speculations surrounding the Brazilian Sign Language (Libras) and many are related to their linguistic features, among them is the question regarding the implementation of the metaphor in a non oralized language. Indeed complex with ramifications in several areas including language and interconnection of education with culture. This study sought grounding in renowned authors that demonstrate the presence of metaphors in the Brazilian language of signs; show the importance of socio - cultural and pragmatic in understanding metaphors to avoid commitment in understanding the meaning for the metaphor in a given context if those involved do not share the same cultural milieu. It is also discussed the fact that the metaphor is seen as a figure of speech and stands out from the others because they believe that the same provides subsidies or even rise to other figures. A bibliographic work that emphasizes a linguistic device widely used in everyday life in a variety of circumstances as to be confused with the language itself.
\end{abstract}

KEYWORDS: Brazilian Sign Language (Libras); Metaphor; Context.

${ }^{1}$ Instituto Ensino Superior Múltiplo - IESM. 


\section{INTRODUÇÃO}

Os estudos científicos desenvolvidos no âmbito linguístico da Língua Brasileira de Sinais (LIBRAS) têm como interesse principal promover o contato entre surdos e ouvintes com a LIBRAS, buscando efetivar a inclusão social de pessoas surdas. De modo que o contato com a língua mencionada entre os ouvintes e surdos fomente a inovação de métodos que propiciem ao surdo instrumentos de compreensão do mundo, de acordo com o meio em que vivem, e aperfeiçoem a capacidade de expressão através de sua língua materna.

Diante de conversações informais com surdos, percebe-se a presença bastante rica de metáforas na construção de frases na língua de sinais. Com o emprego desse artifício as conversas tornam-se mais interessantes, prendem a atenção do interlocutor por tornar o assunto debatido diferente e peculiar, pois o locutor pode transmitir metáforas carregadas de cultura ou podem ser inventadas, criadas, originadas pela própria pessoa para ornamentar a conversa. Na ênfase de determinado assunto pode-se usar a expressão facial junto com o sinal metaforizado como no sinal de admiração: faz-se sinal com a mão aberta, toca-se o queixo em seguida desce a mão e toca na outra também aberta ao tempo em que se abre a boca e usa a expressão facial de admiração.

O presente trabalho utiliza a metodologia bibliográfica embasada em renomados autores da linguística e da estilística que tratam de metáforas como: MARCONI e LAKATOS (2002). BECKER KARNOPP (2004), TONY BERBER SARDINHA (2007), SANDRA PATRÍCIA FARIA (2003) e PRISCILA FREHSE PEREIRA (2007).

A realização desta pesquisa justifica-se pela curiosidade acerca do tema, o que acarretou uma busca instigante por referencial bibliográfico devido à carência de estudos sobre o tema por pesquisadores da área da língua de sinais.

Com este artigo propõe-se alcançar objetivos, tais como, comprovar a existência da metáfora na Língua Brasileira de Sinais, destacar a importância do contexto para a compreensão da metáfora utilizada e sobressaltar a contribuição da cultura para o enriquecimento das metáforas usadas.

A estrutura deste artigo foi elaborada visando a dinamização de sua leitura, por isso, inicia mostrando a necessidade de tratar das figuras de linguagem, destacando a metáfora como a base para as demais. Em seguida, discute algumas definições de metáforas, ao tempo em que enfatiza o contexto como subsídio para sua compreensão. Aborda o uso pragmático do tema, pois é o uso contextualizado de metáforas que torna possível a sua existência e eficácia na comunicação. 


\section{Figuras de linguagem: um destaque para a metáfora}

Quando se possui uma linguagem baseada em uma cultura mais diversifica, mais ampla através de livros, ou de viagens, por exemplo, há grande chance de construir uma conversa com mais figuras de linguagem, e principalmente com mais metáforas. Nesse aspecto, PETTER ${ }^{1}$ assinala que:

como realidade material - organização de sons, palavras, frases - a linguagem é relativamente autônoma; como expressão de emoções, ideias, propósitos, no entanto, ela é orientada pela visão de mundo, pelas injunções da realidade social, histórica e cultural do seu falante. (PETTER 2002, p. 11)

Uma vez que a linguagem do ser é carregada de cultura, engrandecendo-o, tornando-o capaz de expressar-se convenientemente às práticas sociais e o deixando apto à comunicação. PETTER (2002, p. 11), a esse respeito afirma que "a linguagem verbal é, então, a matéria do pensamento e o veículo da comunicação social.” Esse processo comunicativo pode ser através de uma linguagem mais rica de adjetivos, advérbios, verbos ou simplória, no entanto, sempre atingindo seu intento maior, que é efetuar o processo de comunicação.

Os teóricos abordados nesta pesquisa concordam que há uma figura de linguagem especial, pois está mais presente na vida das pessoas, e ainda pode subdividir-se originando outras figuras ou abrindo espaço para o surgimento de novas figuras de linguagem. As figuras enriquecem a linguagem tornando-a mais atraente e enriquece o conteúdo, viabilizando inúmeras possibilidades de significados. Trata-se da metáfora.

Devido a forte ligação existente entre aquisição da metáfora e a aquisição da cultura, no presente trabalho a definição de metáfora adotada é a conceitual pois, permite transmitir experiências e concretizar questionamentos existenciais. Conforme SARDINHA (2007; p. 30), citando LAKOFF (2000): “metáfora conceitual é uma maneira de conceitualizar um domínio de experiências em termos de outro, normalmente de modo inconsciente". *

É um recurso que não extingue os estudos, via que está sempre sendo utilizada, até mesmo sem ser conhecida pelo usuário, porém, muito significativa na formação de sua fala e de seus pensamentos.

Sobre esse fato SARDINHA ${ }^{2}$ lembra que:

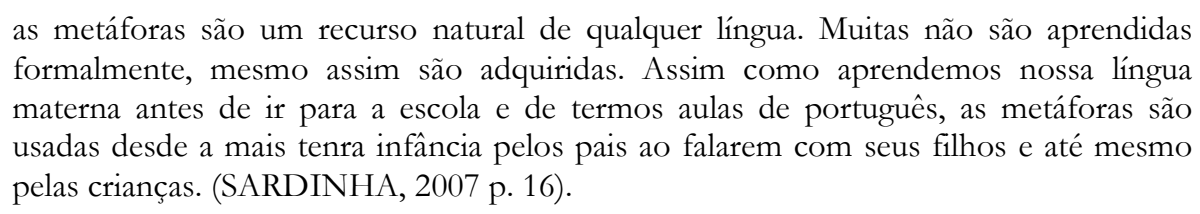

\footnotetext{
${ }^{1}$ PETTTER, Margarida. Linguagem, Língua, Linguística. In: FIORIN, José Luiz (org.) Introdução à Linguística: objetos teóricos. São Paulo, 2002.

${ }^{2}$ SARDINHA, Tony Berber. Metáfora. São Paulo: Parábola, 2007.
} 
O autor compara a metáfora com a própria língua, visto que a língua materna é dominada por uma pessoa quando esta tem livre acesso a ela, isto é, quando se tem convivência com a língua desde o nascimento.

Ainda de acordo com o autor mencionado, ao realizar estudos sobre as metáforas, podese entender melhor como o ser humano conceitualiza o mundo e o que nele existe e ainda, permite compreender o comportamento e ideologias de grupos sociais.

Conforme o autor supracitado, a metáfora está entre as figuras de linguagem porque é vista como figurativa, isto é, ornamenta, embeleza a linguagem, mas também pode definir o estilo de escritores, uma vez estudada como técnica de poetas para expressarem suas emoções e sentimentos, reflexos de uma época retratada em obras literárias.

SARDINHA (2007, p. 23) ressalta que atualmente as metáforas como recurso para reforçar o poder de convencimento de uma pessoa estão sendo estudadas em cursos de oratória. À medida que sua utilidade é ampliada, a metáfora passa a ser tida por muitos como figura primária, de modo que dá origem às outras, como catacrese, eufemismo, personificação etc.

Assim, pode-se ressaltar a definição feita por BECHARA ${ }^{3}$ (2004, p. 397), quando este afirma que a Metáfora é "translação de significado motivada pelo emprego em solidariedades, em que os termos implicados pertencem a classes diferentes, mas pela combinação se percebem também como assimilados".

\section{Metáfora e pragmática}

Os atos linguísticos possuem intenção, visto que a linguagem tem a priori a finalidade de comunicação de interação social, é também uma maneira de o ser humano perceber o mundo ao seu redor e perceber sua realidade. Nesse aspecto, consideram-se as palavras de BECHARA (2004, p. 30), para definir atos linguísticos. Na visão deste gramático, "é cada unidade de comunicação da linguagem humana, seja uma palavra ou uma frase". Sabe-se, no entanto que, ao realizar um ato linguístico possui-se a intenção de comunicar algo a alguém. Com a mensagem transmitida espera-se um feedback, ou seja, deseja-se que o receptor compreenda-a e de alguma forma demonstre essa compreensão, seja explicando o que entendeu ou apenas com um simples gesto, um acenar com a cabeça, por exemplo.

Esse processo constitui a Pragmática da Língua. Assim, o contexto e a intencionalidade juntos com a mensagem tornam-se indissociáveis para uma plena comunicação, PAUL RICOEUR $^{4}$ fundamenta seu pensamento em MARTINICH, quando se posiciona a favor de uma

\footnotetext{
${ }^{3}$ BECHARA, Evanildo. Moderna Gramática Brasileira. 37. Ed. Rio de Janeiro: Lucerna. 2004.

${ }^{4}$ RICOEUR, Paul. A metáfora viva. São Paulo: Parábola, 2000.
} 
teoria na qual a metáfora é de uso pragmático: "é o contexto de uso que determina se um enunciado é pra ser interpretado literalmente ou metaforicamente” (RICOEUR, p. 31, 2000).

Para o escritor RICOEUR a metáfora traz mudança de sentido, um inovação de sentido para uma palavra que mesmo sendo usual, pode adquirir nova significação, pois depende da frase para determinar esse significado. A esse exemplo tem-se FIORIN $^{5}$ (2013, p. 67) citando a palavra laranja, essa pode denotar uma fruta ou a cor advinda da união entre duas cores amarelo e vermelho e pode ainda significar pessoa que empresta o nome para outro cometer fraudes.

Nesses termos adentra-se no campo da pragmática, visto que a pragmática na definição de QUADROS e KARNOPP ${ }^{6}$ é:

\begin{abstract}
o estudo da linguagem em uso (contexto) e dos princípios de comunicação... A pragmática envolve as relações entre a linguagem e o contexto. É uma área que inclui os estudos da dêixis (...), das pressuposições(...) dos atos de fala (...), das implicaturas (...) e dos aspectos da estrutura conversacional (QUADROS e KARNOPP, 2004, p. 22)
\end{abstract}

Nesse aspecto, para tornar uma mensagem passível de compreensão todos os participantes do processo de comunicação devem estar em consonância no mesmo contexto. As palavras principalmente as sinalizadas não podem estar fora de contexto, correndo o risco de serem mal interpretadas ou não interpretadas.

Dentro dessa perspectiva, a comunicação necessita de elementos de indicação, isto é, de elementos dêiticos que demonstram a intenção do falante realçando-a e tornando-a mais clara e concisa para o interlocutor/co-autor.

SARDINHA (2007, p. 50), exemplifica bem a presença de elementos dêiticos quando fala sobre imperativo metaforizado: 'Um imperativo do tipo 'abra a porta!' seria metaforizado em 'você deve abrir a porta.'(...) realizações como 'está calor aquil' como meio de pedir a alguém que abra a porta".

Essa relação entre o ato concreto e a intenção é um forte aliado da cultura. Ela transmite as informações, as teorias que antecederam a um momento histórico pensado e repensado para sua concretude, para sua efetivação. A metáfora serve como instrumento cultural, porque está carregada de significações, que de acordo com o momento histórico sofrem alterações e podem dar novos rumos aos que têm acesso a ela.

$\mathrm{Na}$ língua Brasileira de Sinais (LIBRAS) como em qualquer outra língua existem as metáforas transmitidas pela cultura, intrínsecas à aquisição da linguagem, de modo que existem

\footnotetext{
${ }^{5}$ FIORIN, José Luíz (org.) Linguística? Que é isso? Rio de Janeiro: Contexto, 2013

${ }^{6}$ QUADROS, Ronice Muller de; KARNOPP, Lodenir Becker. Língua de Sinais Brasileira: estudos linguísticos.

Porto Alegre: Artmed, 2004.
} 
metáforas equivalentes na língua portuguesa e outras originárias na LIBRAS, sem equivalentes na LP. Como ressalta PEREIRA ${ }^{7}$ :

\begin{abstract}
a organização conceitual abarca elementos da cultura aliada ao motor cognitivo visual. Em primeiro momento, a ausência de audição era o domínio fonte da metáfora, que vem sendo substituída pela visão, que realmente representa algo da experiência perceptiva destes sujeitos. É a substituição da falta de algo por uma experiência concreta que balisa uma organização cultural específica. A palavra "silêncio" representa uma metáfora "importada" da cultura ouvinte, uma vez que, do ponto de vista dos surdos congênitos, não há como faltar um sentido que nunca foi experimentado. A metaforização da visão representa o que há de mais autêntico em termos da experiência perceptiva dos surdos. $(2007$, p. 64)
\end{abstract}

É notório o fato de os surdos possuírem um desenvolvimento mais complexo da visão, visto que a forma de compreender e apreender o mundo é predominantemente visual, é uma forma de suprir a ausência da audição, porém para o surdo congênito não existe essa ausência, visto que só se pode sentir a falta de algo que já é conhecido, portanto, o surdo aguça a visão em um processo que ocorre de forma lenta constituindo um processo natural. Só descobrindo a ausência de um sentido quando este lhe é relatado por algum ouvinte.

\title{
A presença de metáfora em libras
}

Sabe-se que LIBRAS é uma língua com predominância espaço-visual, de modo que é fácil para um surdo expressar concretamente o que vê, sua percepção visual é mais sensível e aguçada que a dos ouvintes. Desse modo, para um surdo a palavra silêncio não existe e sua compreensão torna-se difícil, visto que ele não conhece sua oposição, que é barulho. Portanto, a palavra "silêncio" não é própria dos surdos e sim emprestada de uma língua oralizada. (PEREIRA, 2007, p.67)

PEREIRA exemplifica sua tese com um vídeo que tratam sobre os efeitos das drogas, no qual as pessoas entrevistadas são na verdade a própria droga, de forma que as pessoas (personificações das drogas) agem e comunicam-se como se fossem os próprios efeitos provocados, ressaltando a metáfora existente nesse vídeo. Neste aspecto, PEREIRA declara que:

esta situação demonstra muito claramente o recurso de personificação. Mas não se trata de um processo perceptível a partir do enunciado, é necessária a análise do contexto para identificar o processo metafórico. Mais uma vez, parte-se da metáfora de possessão objetal: CONTROLE DO SELF É POSSESSÃO OBJETAL, para outra metáfora dela derivada CONTROLAR O CORPO DO OUTRO É TOMAR POSSE DO OUTRO. No uso desta metáfora, no exemplo acima, percebe-se a idéia de que não é mais o subject que controla o self do sujeito, mas o "álcool”. O álcool é que controla as

\footnotetext{
${ }^{7}$ PEREIRA, Priscila Frehse. Psicanálise e surdez: Metáforas Conceituais da Subjetividade em Libras. Curitiba, 2007. Dissertação (Mestrado em Letras - área de concentração em estudos linguísticos) - Setor de ciências Humanas, Letras e Artes, Universidade Federal do Paraná.
} 
pessoas e faz estragos em suas vidas. Trata-se da projeção da experiência de posse para o domínio abstrato do self. (PEREIRA, 2007, p.69)

A pessoa que ali está na verdade é a própria droga, e narra os efeitos provocados pela mesma. A metáfora que reside aqui é o transladar de significados, pois o ator, nesse contexto, perde seu significado dando espaço para significar a própria droga.

Outro exemplo citado pela autora é a metáfora "cabeça vazia", nessa expressão a palavra cabeça é utilizada como lugar onde é possível preencher ou esvaziar quando for necessário, sabese, contudo, que o conhecimento não é algo que se possua como mercadoria fácil, mas é construído ao longo de muito estudo, muita leitura e diversas experiências de vida. "Neste caso, a cabeça é colocada como um lugar que precisa ser "preenchido" através do estudo e da aprendizagem. Tal metáfora é pertinente como estudo das metáforas ontológicas em língua de sinais".

FARIA $^{8}$ (2003, p. 89) na sua dissertação de mestrado faz reflexões sobre metáfora comparativa, isto é, a semelhança entre a forma e o sentido. Em Língua Portuguesa (LP) tem-se a expressão "cara de pau” para descrever uma pessoa de caráter duvidoso, ou seja, incapaz de mudar de expressão facial em situações que provocam constrangimentos à maioria das pessoas.

No entanto, em LIBRAS, essa expressão existe no sinal com a configuração de mão em "A", batendo na face. No sentido de uma superfície dura, "representada" pela face e o movimento de "bater", significando a rigidez da pessoa, e aqui reside a metáfora.

Outro exemplo citado é a expressão "bater papo", a qual constitui uma metáfora, visto que o sinal é constituído pelo movimento de bater a mão levemente no pescoço, local chamado papo em alguns animais, fazendo, neste caso, referência ao fato de esse ser o local da passagem de ar e provocar o som. Porém, a mensagem oculta, nessa expressão, é a de que os surdos fazem esse sinal para designar o fato de estarem conversando de forma despreocupada e informal.

Para confirmar a metáfora existente, pode-se enfatizar a definição exposta no dicionário $\operatorname{HOUAISS}^{9}$ (2003, p. 100), para melhor explicar a metáfora aí presente:

apenas uma ideia livre e descompromissada. Papear equivale a bater papo, trocar ideias, conversar, falar muito, tagarelar. Bater papo é um regionalismo no Brasil, cujo uso é informal, significando troca de ideias; conversa, bate papo, pessoa que gosta de conversar, que tem conversa interessante. (Houaiss, 2001).

\footnotetext{
${ }^{8}$ FARIA, Sandra Patrícia de. A Metáfora na LSB e a Construção dos Sentidos no Desenvolvimento da Competência Comunicativa de Alunos Surdos. Brasília, 2003. Dissertação (Mestrado em Letras - área de concentração em estudos linguísticos) - Departamento de Linguística, Línguas Clássicas e Vernáculas.

${ }^{9}$ Instituto Antônio Houaiss (org.) Minidicionário Houaiss da língua portuguesa. Rio de Janeiro: Objetiva, 2004. 2 Ed. ${ }^{a}$
} 
Ao bater levemente com a mão no pescoço, o surdo deixa subentendido a informação do ato concreto de conversa descompromissada. Existe uma metáfora no sentido de que o ponto de articulação, ou seja, o local onde o sinal acontece, refere-se ao local por onde o ar passa para produzir o som. A compreensão dessa metáfora deve-se ao fator cultural, visto que essa expressão vem da cultura ouvinte, e assim como a palavra silêncio, foi "emprestada" à cultura surda. O fato é que os envolvidos na comunicação possuem o conhecimento de tal expressão obtido através da cultura internalizada por passar de geração a geração.

\section{Considerações finais}

Espera-se, com o presente trabalho comprovar a existência de metáforas na Língua Brasileira de Sinais, e que fazem parte da vida cotidiana das pessoas surdas, espera-se fomentar mais pesquisas nesse campo.

Para isso enfatiza-se o contexto como fator fundamental para o alcance de inovações de sentido de uma palavra. Ele transforma uma conversa e torna-a rica e interessante, pois viabiliza novas significações de um determinado termo. No entanto novas significações são possíveis se os envolvidos no ato da comunicação compartilharem de um mesmo contexto.

Destaca-se a cultura como fator favorecedor dessa riqueza de significações de termos envolvidos em uma conversação contextualizada.

Ressalta que as pesquisas nesse âmbito são de extrema importância, visto que esse é um campo linguístico vasto de descobertas e, no entanto há pouco referencial bibliográfico. Então, é de extrema necessidade a busca e a realização de mais pesquisas nesse campo de estudo.

A metáfora na Língua de Sinais é um evento que participa tanto da organização do pensamento, para uma forma de expressão mais próxima do sentimento e da emoção, quanto da formação cultural do indivíduo, torna-se, portanto, veículo de divulgação das realizações estéticas na livre expressão dos seres humanos que são refletidas em outras gerações culturalmente. 


\section{REFERÊNCIAS:}

BECHARA, Evanildo. Moderna Gramática Brasileira. 37. ed. Rio de Janeiro: Lucerna. 2004.

FARIA, Sandra Patrícia de. A Metáfora na LSB e a Construção dos Sentidos no Desenvolvimento da Competência Comunicativa de Alunos Surdos. Brasília, 2003. Dissertação (Mestrado em Letras - área de concentração em estudos Linguísticos) Departamento de Linguística, Línguas Clássicas e Vernáculas.

FIORIN, José Luíz (org.) Linguística? Que é isso? Rio de Janeiro: Contexto, 2013

Instituto Antônio Houaiss (org.) Minidicionário Houaiss da língua portuguesa. Rio de Janeiro: Objetiva, 2004. $2^{\text {a }}$ Ed.

PEREIRA, Priscila Frehse. Psicanálise e Surdez: Metáforas Conceituais da Subjetividade em Libras. Curitiba, 2007. Dissertação (Mestrado em Letras - área de concentração em estudos linguísticos) - Setor de Ciências Humanas, Letras e Artes, Universidade Federal do Paraná.

PETTER, Margarida. Linguagem, Língua, Linguística. In: FIORIN, José Luiz (org.). Introdução à Linguística: objetos teóricos. São Paulo: Contexto, 2002.

QUADROS, Ronice Muller de; KARNOPP, Lodenir Becker. Língua de sinais brasileira: estudos linguísticos. Porto Alegre: Artmed, 2004.

RICOEUR, Paul. A metáfora viva. São Paulo: Loyola, 2000.

SARDINHA, Tony Berber. Metáfora. São Paulo: Parábola, 2007. 